\title{
PERCEPÇÃO DOS PROFESSORES SUPERVISORES DO PIBID SOBRE AS CONTRIBUIÇÕES E DESAFIOS DO PROGRAMA
}

\author{
PERCEPTION OF PIBID SUPERVISORS ABOUT THE \\ CONTRIBUITIONS AND CHALLENGES OF THE PROGRAM
}

\author{
Leonardo Tavares Martins ${ }^{1}$ \\ Fabianna Evangelista Azevedo ${ }^{2}$ \\ Esaú dos Santos Carvalho ${ }^{3}$ \\ Joatan Silvério da Silva Santos ${ }^{4}$ \\ José Carlos Rodrigues Júnior ${ }^{5}$ \\ Natália Cristina de Oliveira ${ }^{6}$
}

RESUMO: A formação de professores no Brasil é um desafio para as políticas educacionais. Para antecipar o vínculo com a profissão foi criado o PIBID, um programa de bolsas de iniciação à docência que visa favorecer a inserção dos alunos de licenciatura no ambiente escolar, permitindo a articulação entre o ensino superior e a educação básica pública. O objetivo deste trabalho foi identificar a percepção dos supervisores do PIBID sobre as contribuições e desafios do programa. Foi aplicado um questionário aberto e os dados foram analisados qualitativamente. Dentre as contribuições, recebeu destaque o crescimento pessoal e profissional dos bolsistas, que vivenciam a realidade das salas de aula, afirmando sua escolha profissional e preparando-se para a docência. Entre os desafios, foi citado o desenvolvimento de estratégias e métodos para a condução da sala de aula. Conclui-se que o PIBID aproxima a universidade da escola pública na busca pela solução de problemas e desenvolvimento de projetos.

Palavras-chave: Ensino. PIBID. Docentes.

ABSTRACT: The preparation of teachers in Brazil is a challenge for educational policies. To anticipate the teacher's bond with the profession PIBID was created, a scholarship program aiming at promoting the insertion of undergraduation students in the school environment, allowing articulation between higher education and public basic education. The aim of this study was to identify the perception of PIBID supervisors about the contributions and challenges of the program. An open questionnaire was applied and data were analyzed qualitatively. Among the contributions, the personal and professional growth of scholarship recipients were highlighted, as they experience the reality of the classroom, affirming their professional choice and preparing them for teaching. Among the challenges, the development of strategies and methods for conducting the classroom was cited. In conclusion, PIBID

${ }^{1}$ Coordenador da Graduação em Educação Física. Centro Universitário Adventista de São Paulo (UNASP). Email: leonardo.martins@ucb.org.br

${ }^{2}$ Profissional de Educação Física, graduada pelo Centro Universitário Adventista de São Paulo (UNASP). E-mail: fabiazevedo88@gmail.com

${ }^{3}$ Profissional de Educação Física, graduado pelo Centro UNASP. E-mail: esau10edf@ hotmail.com

${ }^{4}$ Profissional de Educação Física, graduado pelo Centro UNASP.E-mail: joatansilverio@ gmail.com

${ }^{5}$ Docente da Graduação em Educação Física. Centro UNASP. E-mail: jose.junior@ucb.org.br

${ }^{6}$ Docente e Pesquisadora do Mestrado Profissional em Promoção da Saúde e da Graduação em Educação Física. Centro Universitário Adventista de São Paulo (UNASP).E-mail: nataliaovs@ gmail.com 
approaches the university and the public schools in the search of problems solution development of projects.

Keywords: Teaching. PIBID. Teachers.

\section{Introdução}

A formação de professores nos cursos de licenciatura no Brasil representa um grande desafio para as políticas educacionais. Os cursos são em geral focados em modelos de aluno e docência que não contemplam o cenário social atual, há um enorme distanciamento entre o ensino superior e o contex to onde o futuro docente atuará (AMBROSETTI et al., 2012).

Ao analisar as taxas de evasão do magistério em diversos países, o relatório da Organização para a Cooperação e Desenvolvimento Econômico (OCDE) de 2006 informou que essas taxas tendem a ser mais altas nos primeiros anos de atividade profissional, declinando à medida em que aumenta o tempo de exercício da profissão (OCDE, 2006).

Como forma de antecipar o vínculo do docente com a profissão, foi criado pela Coordenação de Aperfeiçoamento de Pessoal de Nível Superior (CAPES) em parceria com o governo federal um programa de iniciação à docência, que tem como objetivo favorecer a inserção dos alunos das licenciaturas no ambiente escolar (CAPES, 2013).

Um dos objetivos do Programa Institucional de Bolsa de Iniciação à Docência (PIBID) é trazer o jovem estudante de licenciatura para os processos que fazem parte do cotidiano escolar, gerando assim um significativo crescimento acadêmico (SILVA et al., 2012).

O PIBID teve início em dezembro de 2007, por meio de edital de chamada pública (CAPES, 2008) em ação conjunta do Ministério da Educação, da Secretaria de Educação Superior (SESU), da CAPES e do Fundo Nacional de Desenvolvimento da Educação (FNDE). O programa é dividido em subprojetos por área de conhecimento, com o objetivo de contribuir para a formação do acadêmico nos diferentes âmbitos da formação de um professor, garantindo o aprimoramento do trabalho pedagógico e contribuindo para a melhoria do processo de ensino e de aprendizagem nas escolas de educação básica envolvidas, além de antecipar a vivência no mundo real escolar do futuro docente no período de graduação.

O PIBID oferece bolsas para que alunos de licenciatura exerçam atividades pedagógicas em escolas públicas, visando contribuir para a integração entre teoria e prática. Para assegurar os resultados educacionais pretendidos pelo projeto, os bolsistas são orientados por coordenadores de área, docentes do curso de licenciatura ao qual estão vinculados, e por professores supervisores, docentes das escolas públicas que acompanham cada bolsista durante as atividades (CAPES, 2008). 
As bolsas são concedidas aos participantes de projetos de iniciação à docência desenvolvidos por Instituições de Ensino Superior (IES) em parceria com escolas de educação básica da rede pública de ensino. Os projetos devem promover a inserção dos estudantes no contexto das escolas públicas desde o início da sua formação acadêmica, para que desenvolvam atividades didático-pedagógicas orientadas. As IES interessadas em participar do PIBID apresentam à Capes seus projetos de iniciação à docência conforme os editais de seleção publicados. Podem se candidatar IES públicas, comunitárias, confessionais e filantrópicas que ofereçam cursos de licenciatura (CAPES, 2008). As instituições aprovadas pela Capes recebem cotas de bolsas e recursos de custeio e capital para o desenvolvimento das atividades do projeto. Os alunos bolsistas são escolhidos por meio de seleção promovida em cada IES (CAPES, 2008). Com essa iniciativa, o PIBID faz uma articulação entre a educação superior e as escolas do sistema público de educação básica (MINISTÉRIO DA EDUCAÇÃO E CULTURA, 2013).

A formação de professores pode ser compreendida como a superação de uma formação apenas técnica e no âmbito de seus fundamentos teóricos. Nesse sentido, entende-se o PIBID como um programa que oportuniza a vivência da iniciação no campo da docência em diálogo com a formação teórica oportunizada na universidade, desde que, é claro, tais campos estejam em postura de troca e não de sobreposição de saberes (PIMENTA; LIMA, 2010).

De acordo com Freire (1996, p. 23), "não há docência sem discência, as duas se explicam e seus sujeitos, apesar das diferenças que os conotam, não se reduzem à condição de objeto um do outro. Quem ensina aprende ao ensinar e quem aprende ensina ao aprender".

O aluno de licenciatura pode experienciar tanto o lado discente, pois é aluno da graduação, quanto o lado docente, pois embora nunca esteja sozinho na docência, consegue acompanhar a realidade das atribuições docentes.

No programa objetiva-se uma troca de saberes entre professores supervisores e alunos bolsistas, buscando aproximar as atividades docentes da vida acadêmica dos discentes, trazendo benefícios para a escola pública que recebe os bolsistas, para o estudante de licenciatura e para a IES que o prepara. Os resultados do programa dependem em boa parte dos professores supervisores, uma vez que eles estão em contato constante com os bolsistas, promovendo a intimidade entre eles e a escola. Assim, a identificação da percepção dos professores supervisores sobre o programa fornece boa noção da importância do PIBID para o futuro profissional docente. Mais do que conhecer as contribuições para a escola pública, para as IES e para os alunos de licenciatura, conhecer as fragilidades do PIBID é crucial para que sejam discutidos possíveis ajustes que em última análise poderão beneficiar a educação brasileira. 
Assim, o objetivo deste estudo foi identificar a percepção dos professores supervisores do PIBID acerca das contribuições e desafios do programa para a formação docente, além de reunir informações sobre as contribuições e desafios do programa para a escola pública que recebe os bolsistas.

\section{Método}

Foram convidados a participar deste estudo todos os 29 professores supervisores do PIBID de um Centro Universitário participante do programa, localizado na cidade de São Paulo. O referido Centro Universitário é participante do PIBID desde agosto de 2010, e mantém cursos de licenciatura há quatro décadas. As atividades do PIBID nesta IES se iniciaram em três cursos (Pedagogia, Ciências Biológicas e Matemática) oferecidos por dois campi, com quatro escolas parceiras, totalizando 80 alunos bolsistas, 13 professores supervisores e 5 professores coordenadores. Em 2012 houve a inclusão das licenciaturas em Educação Física, História, Letras e Música, totalizando 167 alunos bolsistas e 29 professores supervisores na época da realização desta pesquisa. ${ }^{7}$

Este estudo caracteriza-se por uma pesquisa qualitativa, conforme proposto por Minayo, Deslandes e Gomes (2008) e foi realizado por meio de questionário enviado por correio eletrônico para os professores supervisores do PIBID. A opção pela pesquisa qualitativa levou em consideração a possibilidade de conhecer, por meio da análise e interpretação dos discursos desses profissionais, a percepção deles sobre as contribuições e os desafios do programa. Utilizamos a Análise de Discurso (AD) para tratamento das respostas.

Conforme a proposta de Orlandi (1995; 1996; 1999; 2001), a AD oferece um dispositivo de análise que explicita a preocupação em identificar um processo de interpretação que vai além do mecanicismo de resultados. O discurso, na perspectiva da ciência, não deve flexionar a sua interpretação a uma metodologia que atente apenas ao conteúdo. A limitação de uma simples interpretação do texto parece não ser suficiente, pois a AD busca "explicitar os processos de significação que trabalham o texto" (ORLANDI, 1999, p. 27). A intenção da AD é compreender o funcionamento do texto, ou seja, como o texto produz sentido e qual é este sentido.

A confirmação de hipóteses, a constatação de um ponto de vista e a previsibilidade são questões descartadas na AD. Procura-se identificar e sustentar a estrutura, a forma, a regularidade, a falha, o equívoco e a contradição, não ignorando todo o contexto de construção

\footnotetext{
${ }^{7}$ Este estudo foi aprovado pelo Comitê de Ética em Pesquisa local (Parecer no 415.387).
} 
do discurso. A AD busca desvendar os mecanismos de dominação que se escondem sob a linguagem, não se tratando nem de uma teoria descritiva, nem explicativa, mas sim de uma proposta crítica que problematiza as formas de reflexão já estabelecidas (CAPPELLE et al., 2003).

Assim, todos os professores supervisores do PIBID vinculados ao Centro Universitário em questão foram convidados a participar da pesquisa por meio de correio eletrônico. O contato eletrônico dos supervisores foi solicitado à coordenação institucional do PIBID e o e-mail enviado a cada um deles continha um convite à participação e cinco questões abertas, referentes à percepção dos professores supervisores em relação ao programa, incluindo os seguintes itens: pontos positivos para os alunos de licenciatura, benefícios para escola e para os alunos, pontos negativos do início precoce do bolsista no programa, problemas ou situações negativas e de risco, vantagens e possibilidades do programa.

\section{Resultados}

Dos 29 supervisores convidados a participar da pesquisa apenas sete responderam ao questionário, após duas solicitações com uma semana de intervalo entre cada uma. Os respondentes eram supervisores das áreas de Educação Física (n=2), Música (n=2) e Matemática $(\mathrm{n}=3)$.

Os quadros expostos a seguir foram compostos pelas unidades de significado extraídas das respostas dos supervisores. Os números em algarismos romanos fazem referência aos participantes da pesquisa.

Quadro 1 - Pontos positivos do PIBID segundo relato dos supervisores

\begin{tabular}{|c|l|}
\hline I & $\begin{array}{l}\text { Facilita a experiência em sala de aula. } \\
\text { Aprendizagem didática. } \\
\text { Preparação para o mercado de trabalho. }\end{array}$ \\
\hline II & $\begin{array}{l}\text { Possibilidade de ministrar aulas e ver o que dá certo ou não. } \\
\text { Discussão com o supervisor sobre o que é ou não interessante de trabalhar em sala de aula. } \\
\text { Firmar o desejo de dar aulas. } \\
\text { Definir qual é o seu perfil de professor. } \\
\text { Visão de qual nível escolar está apto a lecionar. } \\
\text { Troca de experiências e informações que acontecem entre bolsistas e professores. }\end{array}$ \\
\hline III & $\begin{array}{l}\text { Adquirir experiência de sala de aula. } \\
\text { Colocar em prática os ensinos teóricos. }\end{array}$ \\
Aperfeiçoar a didática. \\
Ganhar confiança e segurança para ingressar no mercado de trabalho.
\end{tabular}




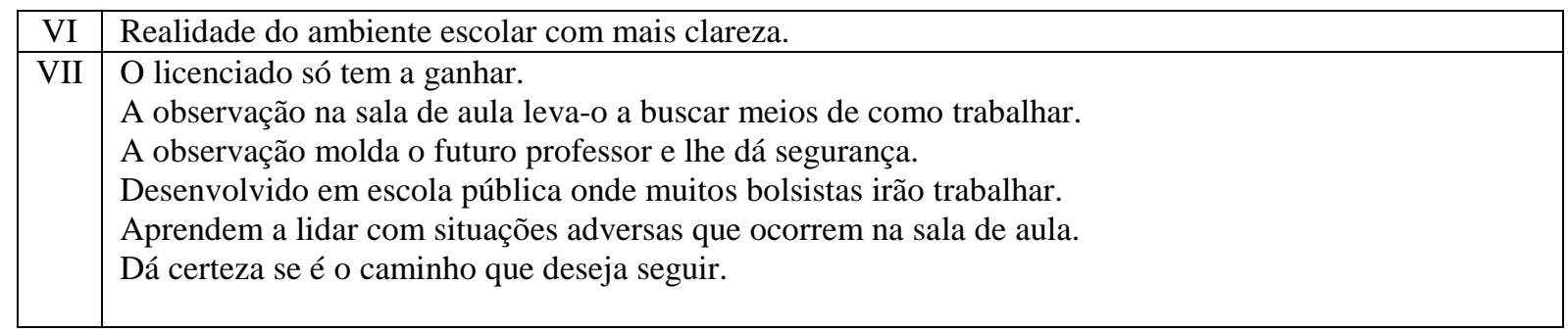

Fonte: Dados da pesquisa.

O Quadro 1 revela, de acordo com as respostas dos supervisores, os principais pontos positivos do PIBID para os alunos de licenciatura. Os supervisores destacaram itens como a preparação para o mercado de trabalho, a afirmação do desejo de ser professor e a forma como o programa facilita a experiência da vivência em sala de aula.

\section{Quadro 2 - Benefícios do PIBID para a escola e seus alunos}

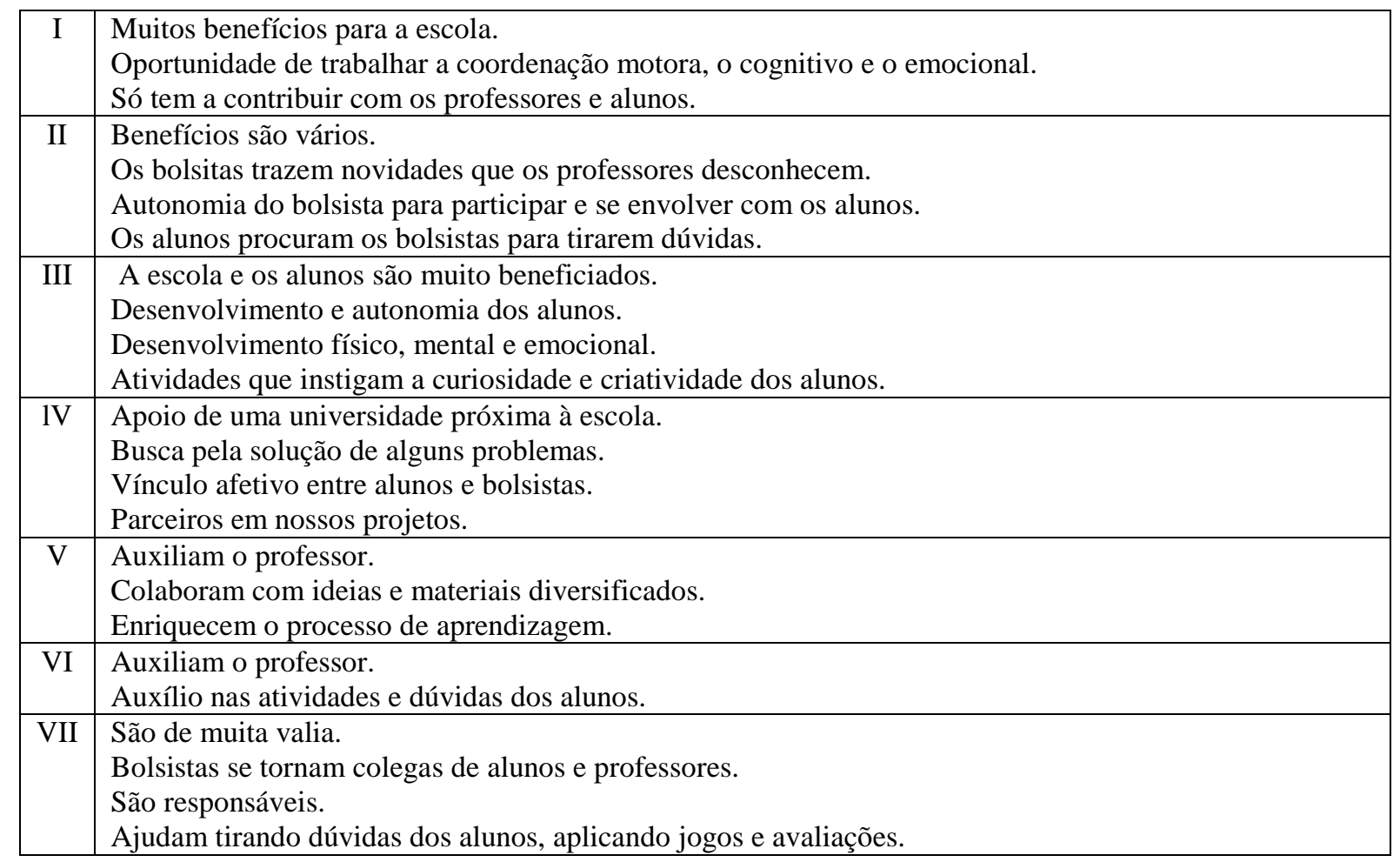

Fonte: Dados da pesquisa.

O Quadro 2 apresenta, de acordo com as respostas dos supervisores, os benefícios para a escola e para os alunos do ensino básico. Há a menção a questões genéricas, como "muitos benefícios para a escola" e específicas, tais como a menção à autonomia e a responsabilidade.

Quadro 3 - Pontos negativos do início precoce no programa

\begin{tabular}{|c|l|}
\hline I & $\begin{array}{l}\text { Sem domínio em sala de aula. } \\
\text { Conhecimento didático. }\end{array}$ \\
\hline II & Não há pontos negativos. \\
\hline III & $\begin{array}{l}\text { Dificuldade com o domínio de sala. } \\
\text { Falta de experiência. }\end{array}$ \\
\hline
\end{tabular}




\begin{tabular}{|c|l|}
\hline IV & Impulsividade e falta de equilíbrio emocional. \\
\hline V & Falta de comprometimento de alguns bolsistas. \\
\hline VI & Não há pontos negativos. \\
\hline VII & Não vejo pontos negativos. \\
\hline
\end{tabular}

Fonte: Dados da pesquisa.

O Quadro 3 revela a percepção dos professores supervisores sobre os possíveis pontos negativos associados ao início precoce do bolsista nas escolas. Destaca-se a menção de 3 supervisores de que não há pontos negativos.

Quadro 4 - Problemas, situações negativas e de risco

\begin{tabular}{|c|l|}
\hline I & Não causam risco algum. \\
\hline Il & Não vejo problema situação negativa ou risco para a escola. \\
\hline Ill & De forma alguma, só trazem benefícios para a escola e os alunos. \\
\hline IV & Não há o que temer. \\
\hline V & Acredito que seja relativo. \\
\hline V1 & Só se eles se tornarem responsáveis pelas aulas. \\
\hline Vll & $\begin{array}{l}\text { Não causam problema algum. } \\
\text { Desde que os bolsitas sejam esclarecidos sobre o que podem ou não fazer em sala. Que momentos } \\
\text { eles podem interferir e o que relatar. }\end{array}$ \\
\hline
\end{tabular}

Fonte: Dados da pesquisa.

O Quadro 4 apresenta a percepção dos professores supervisores em relação aos possíveis problemas ou situações negativas e de risco. Mais uma vez se repete a ideia de que não há problemas ou riscos.

Quadro 5 - Vantagens e possibilidades do PIBID

\begin{tabular}{|c|l|}
\hline I & $\begin{array}{l}\text { Conhecimento da disciplina lecionada. } \\
\text { Complemento financeiro para o bolsista. }\end{array}$ \\
\hline II & $\begin{array}{l}\text { Troca de experiências. } \\
\text { A proximidade da universidade através do PIBID nas escolas é útil para o desenvolvimento de novas } \\
\text { estratégias para a prática docente mais eficiente e verdadeira. }\end{array}$ \\
\hline III & $\begin{array}{l}\text { Contato direto com a realidade de forma prática. } \\
\text { Auxílio financeiro para os estudantes. } \\
\text { Professores supervisores aperfeiçoam seus conhecimentos e se envolvem mais com a escola. }\end{array}$ \\
\hline IV & $\begin{array}{l}\text { Troca de conhecimento. } \\
\text { Melhora a formação do aluno na escola. } \\
\text { Melhora a formação do bolsista na faculdade. }\end{array}$ \\
\hline V & $\begin{array}{l}\text { Cria muitas possibilidades. } \\
\text { Traz muito conhecimento e experiências aos bolsistas. } \\
\text { Oportunidade de vivenciar, analisar e interagir no cotidiano escolar. } \\
\text { Troca de conhecimento entre bolsistas e professores. } \\
\text { Acrescenta muito em sua vida profissional. } \\
\text { Formação de docentes mais preparados e capacitados. }\end{array}$ \\
\hline VI & $\begin{array}{l}\text { Ter desde cedo a visão da profissão que está estudando. } \\
\text { Conhecer o dia-a-dia do ambiente escolar e suas peculiaridades. }\end{array}$ \\
\hline VII & $\begin{array}{l}\text { As vantagens são muitas. } \\
\text { Conteúdos trabalhados de maneiras diferenciadas. } \\
\text { Profissionais falando a mesma língua e tirando dúvidas dos alunos ao mesmo tempo. }\end{array}$ \\
\hline
\end{tabular}

Fonte: Dados da pesquisa.

A última questão abordou as vantagens, possibilidades e a importância do PIBID na formação de novos docentes. As respostas estão apresentadas no Quadro 5. Mais uma vez há 
expressões genéricas, mas também aparecem menções específicas como a questão financeira e a troca de conhecimento.

\section{Discussão}

O objetivo deste estudo foi identificar a percepção dos professores supervisores do PIBID sobre o programa. A maioria deles destacou pontos positivos com menções genéricas, expressando satisfação de uma forma geral com o programa. Não houve menção a pontos negativos ou que causassem grandes preocupações decorrentes do programa.

Um estudo sobre o PIBID realizado na Universidade Federal de Rondônia destacou o importante papel da inserção precoce do futuro docente na educação básica (SILVA et al., 2012). Pesquisa realizada com bolsistas do PIBID da Universidade Federal do Estado do Rio de Janeiro (FETZNER; SOUZA, 2012) ressaltou a importância do programa em integrar não apenas o conhecimento universitário à prática docente, mas também os saberes dos estudantes das escolas públicas ao conteúdo trabalhado na escola. Os autores ressaltam, ainda, o valor desta aprendizagem em meio à tradição docente de separar e desvalorizar a experiência dos alunos dos saberes propostos pela escola.

Considerando a enorme distância entre a realidade de vida de um aluno de licenciatura e aquela de um professor de ensino básico, e, ainda, que a proposta do PIBID é favorecer a inserção do aluno de licenciatura no cotidiano escolar, identificamos uma efetiva relação entre a proposta e o que de fato acontece com as personagens envolvidas no programa. Nas respostas, há a expressão recorrente de satisfação e de que o programa contribui efetivamente para o aperfeiçoamento da formação docente. Subentende-se que o programa tem de fato permitido a aproximação do aluno de licenciatura da realidade escolar.

Os professores supervisores auxiliam os bolsistas no processo de adaptação ao ensino básico, e ao mesmo tempo o bolsista traz novidades apresentadas ou desenvolvidas no curso de graduação que os professores podem passar a aplicar em suas práticas.

A formação de professores deve ter como fundamento o professor que se quer formar, consciente da realidade e do cotidiano escolar. Assim o PIBID se propõe a contemplar essa necessidade. Neira (2010, p. 58), ao discutir a questão do currículo propõe que:

Os saberes e situações que constituem o currículo da formação para a docência refletem, em última análise, o sujeito-professor que se quer formar. Sempre há um projeto de cidadão em vista e um modelo profissional a ser alcançado para um determinado projeto de sociedade.

Assim, a experiência prática que o PIBID privilegia facilita que o professor a ser formado seja consciente das condições pedagógicas reais. 
Nesse estudo, apesar de termos pesquisado professores de áreas diferentes, notamos por meio das respostas que todos possuem a mesma linha de pensamento em relação às contribuições que o programa traz aos bolsistas. Segundo eles, a participação no PIBID ajuda o bolsista a adquirir experiência de sala de aula, observando o que é certo ou errado, pontos positivos e negativos, conflitos e suas possíveis soluções, como portar-se em situações desafiadoras e adversas. O programa também possibilita a oportunidade de atuação nas aulas em atividades conjuntas com o professor supervisor, colocando em prática os conhecimentos adquiridos na IES. Os professores coordenadores, docentes da IES, promovem encontros e discussões que também facilitam o diálogo entre teoria e prática, entre o que é visto nos artigos estudados e produzidos com aquilo que se faz em nas situações de aula.

Os professores supervisores acreditam que o PIBID proporciona ao bolsista a possibilidade de adquirir experiência em sala de aula. Isso significa a oportunidade de vivenciar diversas situações do cotidiano do professor, algo que muda de turma para turma. Essa vivência é uma experiência singular, pois durante o curso de graduação, mesmo a melhor explicação sobre essa realidade não é comparável à experiência prática. A revisão de currículo e conteúdo permeia essa discussão, como reforça Gatti (2010, p.1359):

Hoje, em função dos graves problemas que enfrentamos no que respeita às aprendizagens escolares em nossa sociedade, a qual se complexifica a cada dia, avoluma-se a preocupação com as licenciaturas, seja quanto às estruturas institucionais que as abrigam, seja quanto aos seus currículos e conteúdos formativos.

Ainda assim, a revisão de conteúdos e currículo pode se restringir aos conceitos. Por isso o PIBID, ao agregar experiência prática às discussões sobre o cotidiano da vida escolar, agrega valores perceptíveis.

Exemplos de tais situações práticas incluem a maneira de lidar com turmas mal comportadas, ferramentas que o professor tem em mãos para resolver problemas, formas de ação em caso de conflito entre alunos, falta de estrutura por parte da escola e postura diante da falta de materiais de aula. Essas situações se transformam em uma bagagem de experiências, pois são situações rotineiras que fazem parte do dia-a-dia do docente. Vieira, Caires e Coimbra (2011) argumentam sobre a importância desse tipo de aprendizagem que envolve a prática:

[...] as aprendizagens mais significativas e duradouras são as que decorrem de experiências concretas e da experimentação ativa, implicando o envolvimento direto dos formandos em atividades e contextos reais de trabalho (VIEIRA; CAIRES; COIMBRA, 2011, p. 30).

A aprendizagem pode ser concebida como um problema à espera de solução (POZO, 2002). Sua solução necessitará de um treinamento ou uma prática adequada para esse fim, 
decorrentes de uma experiência concreta. Dessa forma, uma boa aprendizagem requer uma prática bem organizada. A ausência da relação teoria-prática é apontada como uma das causas da insegurança por parte de recém-formados, conforme aponta Gondim (2002, p. 307):

[...] as poucas oportunidades de exercício prático oferecidas durante o processo de graduação, e que estão relacionadas com as dificuldades de se articular de modo integrado a formação científica e a profissionalizante, contribuem para o sentimento de insegurança experimentado pelo estudante, para o delineamento de um perfil fragmentado e para a fragilização na construção de uma identidade profissional que prejudicam a visualização de perspectivas concretas de inserção no mercado de trabalho.

A proposta de vivenciar o cotidiano da vida escolar e com acompanhamento docente garante a articulação entre saber e fazer, minimizando as fragilidades e insegurança da entrada no mercado de trabalho.

De acordo com a percepção dos professores supervisores, os bolsistas trazem muitos benefícios para a escola, desenvolvem projetos diferenciados, colocam em prática o conhecimento adquirido, prestam suporte ao professor durante as aulas, observando a sala enquanto o professor resolve algum problema e tirando dúvidas dos alunos.

Considerando inquestionável que "a qualidade da educação pressupõe um professor bem formado" (VASCONCELOS, 2013, p. 4), a aproximação da formação profissional com a prática da profissão reforça a ideia de que a boa formação produzirá bons docentes.

Para a maioria dos professores supervisores não há pontos negativos relacionados à presença do bolsista na escola. O bolsista é um aprendiz sob a supervisão de um profissional experiente, sendo assim toda e qualquer atividade realizada por um bolsista é previamente analisada por seu supervisor

O início precoce no programa pode trazer insegurança e dificuldades para os bolsistas, mas em que pese esse risco, é também um bom momento para a aquisição de experiência sob supervisão direta. Embora seja verdade que o distanciamento da formação docente do mundo real seja apontado como algo recorrente em várias áreas, o PIBID se propõe a diminuir essa distância, não permitindo que o egresso do ensino superior tenha conhecido a realidade escolar apenas virtualmente.

Na percepção dos supervisores a presença do bolsista na escola não traz nenhum risco. O bolsista está na escola com o intuito de aprender e de colocar em prática os conhecimentos adquiridos na IES, ainda não tem responsabilidade sobre os problemas que eventualmente possam surgir e não deve interferir na aula, já que esse papel pertence ao do professor. 
Além dos pontos positivos para os bolsistas, a participação deles traz benefícios para a escola e também para os alunos. Para a escola fica a certeza do apoio de uma IES próxima, na busca pela solução de problemas e parcerias em projetos. Já para os alunos da educação básica, o bolsista se torna uma espécie de segundo professor que pode tirar dúvidas e auxiliar em diversas atividades, cooperando no aprendizado da turma e facilitando o vínculo entre aluno e escola.

Outro ponto de destaque nos comentários dos supervisores é o desenvolvimento da autonomia docente. O PIBID permite a intervenção do bolsista sem reduzi-lo a um reprodutor de ações, mas estimulando sua intervenção por meio de criação e discussão das propostas curriculares, do estudo teórico e de sua aplicação prática.

Por fim, um ponto relevante para os alunos de graduação é o auxílio financeiro que o programa prevê, muitas vezes utilizado para custear os estudos. Embora o valor não lhes garanta independência, traz auxílio num momento importante da vida. Poder vivenciar a experiência que o programa permite recebendo um auxílio financeiro é algo que os supervisores reconhecem como parte importante do programa.

\section{Conclusão}

Na visão dos supervisores, o PIBID cumpre com seu compromisso de aproximar o discente de licenciatura da realidade profissional da sua área de atuação, dando-lhe a chance de colocar em prática os conhecimentos por ele obtidos no ensino superior, e garantindo a oportunidade de adquirir experiência do cotidiano e da realidade de sua futura profissão. A experimentação prática no ambiente de trabalho permite amadurecimento acompanhado de crescimento pessoal e profissional, contribuindo para que o futuro docente defina seu papel de professor, reforçando seu desejo de atuação, contribuindo para desenvolver estratégias que lhe tragam confiança e segurança para assumir uma sala de aula. Os benefícios se estendem também à escola de ensino básico que recebe os bolsistas e às IES, por fomentar discussões relativas à profissão docente e suas atribuições.

\section{REFERÊNCIAS}

AMBROSETTI, N. B.; TEIXEIRA, M.B.; RIBEIRO, M.T.M. A experiência do PIBID na perspectiva dos formadores das licenciaturas. XVI ENDIPE - Encontro Nacional de Didática e Práticas de Ensino. Campinas: UNICAMP, 2012.

COORDENAÇÃO DE APERFEIÇOAMENTO DE PROFISSIONAIS DE ENSINO SUPERIOR (CAPES). Programa Institucional de Bolsa de Iniciação à Docência (PIBID), 2008. Disponível em: http://www.capes.gov.br/educacao-basica/capespibid. Acesso em: 16 maio 2018. 
CAPPELLE, M. C. A.; MELO, M.C.O.L.; GONÇALVES, C.A. Análise de conteúdo e análise de discurso nas ciências sociais. Organizações Rurais \& Agroindustriais - Revista Eletrônica de Administração, da UFLA, v. 5, n.1, 2003.

FETZNER, A. R.; SOUZA, M.E.V. Concepções de conhecimento escolar: potencialidades do Programa Institucional de Bolsa de Iniciação à Docência. Revista Educação e Pesquisa, São Paulo, Universidade Federal do Estado do Rio de Janeiro, 2012.

FREIRE, P. Pedagogia da autonomia: saberes necessários à prática educativa. 39. ed. São Paulo: Paz e Terra, 1996.

GATTI, B. A. Formação de professores no Brasil: características e problemas. Educ. Soc., Campinas, v. 31, n. 113, p. 1355-1379, out./dez. 2010.

GONDIM, S. M. G. Perfil profissional e mercado de trabalho: relação com a formação acadêmica pela perspectiva de estudantes universitários. Estudos de Psicologia, v. 7, n. 2, p. 299-309, 2002.

MINAYO, M. C. S.; DESLANDES, S.F.; GOMES, R. Pesquisa social: teoria, método e criatividade. 27. ed. Petrópolis: Vozes, 2008.

MINISTERIO DA EDUCAÇÃO E CULTURA. Programa Institucional de Bolsa de Iniciação à Docência (PIBID). Disponível em: <http://portal.mec.gov.br/index.php?Itemid= 467\&id=233\& option=com_content\&view=article $>$ Acesso em: 04 abr. 2013.

NEIRA, M. G. Desvelando frankensteins: interpretações dos currículos de licenciatura em Educação Física. Revista Mackenzie de Educação Física e Esporte. São Paulo: v. 9 (Suplemento 1), p. 55-59, 2010.

ORGANIZAÇÃO PARA A COOPERAÇÃO E DESENVOLVIMENTO ECONÔMICO (OCDE). Professores são importantes: atraindo, desenvolvendo e retendo professores eficazes. Relatório de Pesquisa. São Paulo: Moderna, 2006.

ORLANDI, E. P. Efeitos do verbal sobre o não-verbal. Revista do Nudecri, Campinas, n.1, p. 35-47, 1995.

ORLANDI, E. P. Interpretação: autoria, leitura e efeitos do trabalho simbólico. Petrópolis: Vozes, 1996.

ORLANDI, E. P. Análise de discurso: princípios e procedimentos. Campinas: Pontes, 1999.

ORLANDI, E. P. Discurso e texto: formação e circulação dos sentidos. Campinas: Pontes, 2001.

PIMENTA, S. G.; LIMA, M. S. L. Estágio e docência. 5. ed. São Paulo: Cortez, 2010.

POZO, J. I. Aprendizes e mestres: a nova cultura da aprendizagem. Porto Alegre: Artmed, 2002.

SAVIANI, D. Formação de professores: aspectos históricos e teóricos do problema no contexto brasileiro. Revista Brasileira de Educação, v. 14, n. 40, p. 143-155, jan./abr. 2009.

SILVA. L. G. F; LOPES, R. L. S. U.; SILVA, M. F.; TRENNEPOHL JÚNIOR, W. Formação de professores de Física: experiência do PIBID, da Faculdade de Educação Física da Universidade Federal de Rondônia. RBPG, Brasília, v. 9, n. 16, p. 213 - 227, abr. 2012.

VASCONCELOS, M. L. M. C. Formação docente e qualidade da educação: um binômio inseparável. Verbum - Cadernos de Pós-graduação, n. 4, p. 4-10, 2013. 
VIEIRA, D.A.; CAIRES, S.; COIMBRA, J.L. Do ensino superior para o trabalho: contributo dos estágios para inserção profissional. Rev. Bras. Orient. Prof., São Paulo, v. 12, n. 1, jun. 2011.

Relato recebido em: 10/04/2017

Relato aceito em: 25/09/2017 